Research Article

\title{
Optimized Size and Tab Width in Partial Solar Cell Modules including Shingled Designs
}

\author{
Julius Roeth, Arrigo Facchini, and Norbert Bernhard \\ Anhalt University of Applied Sciences, 06366 Köthen, Germany \\ Correspondence should be addressed to Julius Roeth; julius.roeth@hs-anhalt.de
}

Received 21 July 2017; Revised 3 October 2017; Accepted 12 October 2017; Published 16 November 2017

Academic Editor: Francesco Riganti Fulginei

Copyright ( 2017 Julius Roeth et al. This is an open access article distributed under the Creative Commons Attribution License, which permits unrestricted use, distribution, and reproduction in any medium, provided the original work is properly cited.

\begin{abstract}
Cell-to-module loss (CTM loss) is defined by optical and electrical losses. Using partial solar cells can reduce ohmic losses. Today, some manufactures use halved cells even if they have to employ extra effort for sorting, placing, and soldering the solar cells. In this work, the advantage of partial solar cells is described. An LTSpice simulation is used to quantify the reduced ohmic loss and the resulting efficiency gain for differently separated solar cells. This efficiency gain is compared with the whole module area caused by the tab and cell areas. The additional gain due to the backsheet reflection is added afterwards. It can be pointed out that the use of half cells is a technical optimal application while not using shingled modules.
\end{abstract}

\section{Introduction}

The key task of solar module production is the reduction of the CTM loss. Solar cell partitions connected in series reduces the ohmic loss in respect to a whole solar cell. Previous publications were focused on half cells $[1,2]$. For smaller cell partitions (e.g., 1/3, 1/4, ...), only rare information is available. For this reason, especially, smaller partitions were investigated in this work. An already published simulation model for the half-cell application has been extended [1]. This extension is focused on 1 to 16 timesdivided solar cells. Furthermore, the resulting efficiency gain due to the reduced current is compared with the nonactive module area caused by the enlarged tab area. In addition to this, the backsheet reflection (i.e., the light reflected by the tab width surface) has been simulated. This procedure allows the detection of the optimal cell size in combination with different tab widths for conventional module applications.

\section{Theory and Simulation}

2.1. Ohmic Losses. When solar cells are connected in series (forming a so-called cell string), the string voltage is the sum of the single cell voltages, while the string current remains equal to the single cell current. For this reason, dividing a whole cell into $n$-partial cells causes a $1 / n$-times decrease in current. Thus, the ohmic loss is reduced. The dependence of the ohmic loss $P_{\text {ohmloss }}$ on the current is described by the following equation:

$$
P_{\text {ohm loss }}=R_{\mathrm{S}} \cdot I^{2} \text {. }
$$

Since the major influence on the ohmic loss is the squared current, while the series resistivity $R_{\mathrm{S}}$ has a linear influence, it is more beneficial to reduce the former.

The resistivity can be described as the sum of the cell resistivity $R_{\mathrm{C}}$ and the resistivity of the interconnection via ribbon $R_{\mathrm{R}}[1]$.

$$
R_{\mathrm{S}}=R_{\mathrm{C}}+R_{\mathrm{R}}
$$

The cell resistivity $R_{\mathrm{C}}$ is the sum of various resistances and is affected by the size of the solar cell. Figure 1 illustrates the composition of $R_{\mathrm{C}}$ in a solar cell along the back contacting $\left(R_{\mathrm{AL}}, R_{\mathrm{CB}}\right)$, the silicon crystal $\left(R_{\mathrm{B}}, R_{\mathrm{E}}\right)$, and the fingers $\left(R_{\mathrm{CF}}, R_{\mathrm{F}}\right)$ [3]. In this model, the resistances of the busbar $\left(R_{\mathrm{BB}}, R_{\mathrm{CB}}\right)$ are included in $R_{\mathrm{R}}$ as a reason of the parallel connection.

Looking at the cross-section of the individual resistors, it is noticeable that they are dependent on the size of the solar cell. Especially, $R_{\mathrm{B}}$, which has the highest influence on the cell resistivity $R_{\mathrm{C}}$, is highly dependent on the size of the solar cell. 


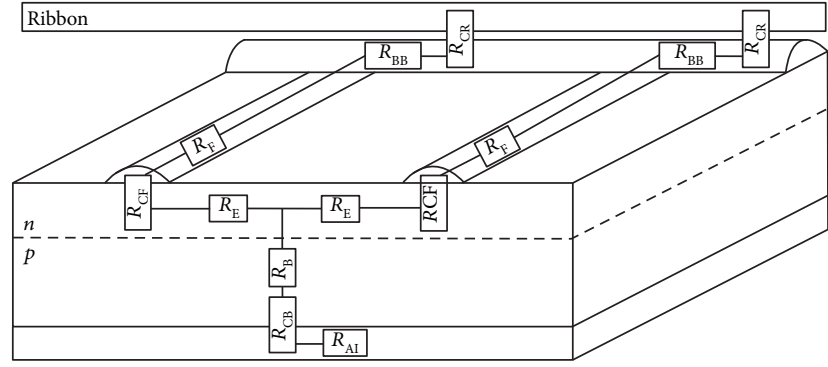

FIGURE 1: Schematic representation of the solar cell series resistivity.

For this reason, $R_{\mathrm{C}}$ is normalized to the cell area (a typical value for $R_{\mathrm{C}}$ of $0.6 \Omega \cdot \mathrm{cm}^{2}$ was used). The resistance of the ribbon $R_{\mathrm{R}}$ is different and is defined by the following equation [1]:

$$
R_{\mathrm{R}}=\frac{2 r \cdot L_{\mathrm{bb}}}{3 N_{\mathrm{bb}}},
$$

where $r$ is the specific resistance $(\Omega / \mathrm{m})$ of the ribbon and the busbar in parallel, $L_{\mathrm{bb}}$ the length $(\mathrm{m})$ of the busbar, and $N_{\mathrm{bb}}$ the amount of busbars. The cross-section of a given busbar and ribbon combination will not change and is already included in the specific resistance $r(\Omega / \mathrm{m})$. The length $L_{\mathrm{bb}}$ and the number of busbars have a linear influence on the resistance $R_{\mathrm{R}}$.

Therefore, the whole series resistivity $R_{\mathrm{S}}$ depends on the width and size of the solar cell and must be calculated for each cell partition. To describe the circuit behavior, an LTSpice simulation model was created. This model is described in the following section.

2.2. Simulation Model. A one-diode model (see Figure 2) was used to simulate the solar cell I-V characteristic curve. For this study, the electric circuit simulator program LTSpice was used. Depending on the amount of partial cells, an equal number of elementary circuits like the one in Figure 2 were connected in series. The corresponding values in Table 1 were entered afterwards. The values were based on a previous work [1] and extended to partial cell applications.

Every circuit from 1 to 16 partial cells was simulated for two different photocurrent densities, (35 and $42 \mathrm{~mA} / \mathrm{cm}^{2}$ ) in order to represent two different cell qualities at a given irradiance. An additional electrical loss due to the cell separation of about $1 \%$ rel. is presented in the literature [4] but not carried out in this work. This neglect should be kept in mind. A total amount of $32 \mathrm{I}-\mathrm{V}$ curve simulations were executed. From the maximum power point $\left(P_{\mathrm{mpp}}\right)$, the short-circuit current $\left(I_{\mathrm{sc}}\right)$ and the open-circuit voltage $\left(V_{\mathrm{oc}}\right)$ of each I-V curve, the theoretical efficiency $\eta_{\text {circuit }}$ was calculated as follows:

$$
\eta_{\text {circuit }}=\frac{P_{\mathrm{mpp}}}{1000\left(\mathrm{w} / \mathrm{m}^{2}\right) \cdot A} .
$$

The results are discussed in Section 3.1. Aside from that, the tab width between each partial cell increases the whole module area while not using shingled module designs which

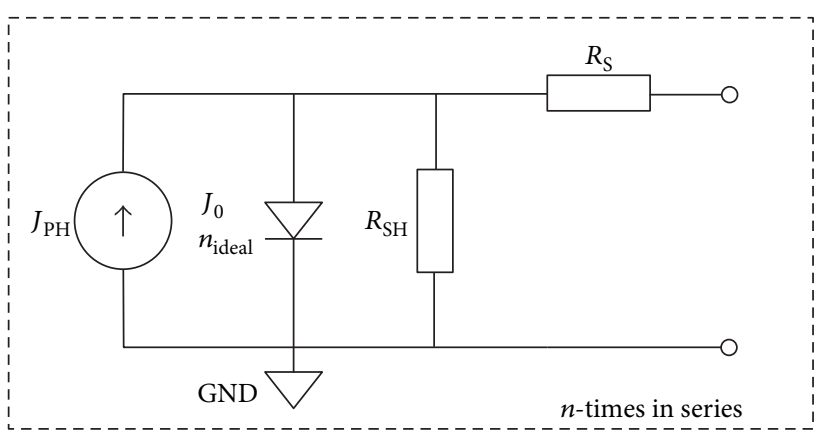

FIgURE 2: Elementary equivalent circuit of a solar cell. The components are series resistivity $R_{\mathrm{S}}$, shunt resistivity $R_{\mathrm{SH}}$, photo current $J_{\mathrm{PH}}$, saturation current $J_{0}$, and ideality factor of solar cell $n_{\text {ideal }}$.

TABle 1: Simulation data for the circuit shown in Figure 2. The simulation was repeated for an increasing number of cell partitions and for two different photocurrent densities. The series resistance is the sum of $R_{\mathrm{C}}$ and $R_{\mathrm{R}}$.

\begin{tabular}{lcccccc}
\hline $\begin{array}{l}A \\
\left(\mathrm{~cm}^{2}\right)\end{array}$ & $\begin{array}{c}J_{\mathrm{PH}} \\
\left(\mathrm{mA} / \mathrm{cm}^{2}\right)\end{array}$ & $\begin{array}{c}J_{0} \\
\left(\mathrm{pA} / \mathrm{cm}^{2}\right)\end{array}$ & $\begin{array}{c}R_{\mathrm{SH}} \\
\left(\mathrm{k} \Omega \cdot \mathrm{cm}^{2}\right)\end{array}$ & $\begin{array}{c}R_{\mathrm{C}} \\
\left(\Omega \cdot \mathrm{cm}^{2}\right)\end{array}$ & $\begin{array}{c}R_{\mathrm{R}} \\
(\mathrm{m} \Omega / \mathrm{m})\end{array}$ & $\begin{array}{c}n_{\text {ideal }} \\
-\end{array}$ \\
\hline 243.36 & 35 & 2 & 10 & 0.6 & 12.79 & 1.02 \\
& 42 & & & & & \\
\hline
\end{tabular}

only uses interstring tabs [5]. To compensate this effect, it is necessary to normalize the efficiency by the whole module area as described in the following section.

2.3. Tab Width Compensation. Figure 3 illustrates how the one-cell-module area increases due to cell separation. The additional tab resulting from the cell separation is marked in grey. $n$ is the number of partial cells $(n=1$ and $n=2$ are shown in Figure 3), $A$ is the cell area, $d$ is the length of the cell edge (equal to $15.6 \mathrm{~cm}$ ), and $d_{\mathrm{tw}}$ is the tab width.

If we assume that the whole module area is defined by the cell area $A=d^{2}$ and the tab area $4\left(d+d_{\mathrm{tw}}\right) d_{\mathrm{tw}}$, then each cell separation increases the module area of one additional tab $\left(2 d_{\mathrm{tw}}+d\right) d_{\mathrm{tw}}$ (the tab area corresponds to the area of the frame around the cell, which can be expressed as $4 d_{\mathrm{tw}}{ }^{2}+4 d d_{\mathrm{tw}}$; the same applies for the additional tab: $\left.2 d_{\mathrm{tw}}{ }^{2}+d d_{\mathrm{tw}}\right)$. This model does not include a difference between the intercell spacing area and the tab width area. A previous study on partial cells shows that the tab width should be optimized for the different partial cell application [6]. Thus, several tab widths were simulated later on. The whole module area can be calculated as follows:

$$
A_{\text {module }}=A+4\left(d+d_{\mathrm{tw}}\right) d_{\mathrm{tw}}+(n-1)\left(2 d_{\mathrm{tw}}+d\right) d_{\mathrm{tw}} .
$$

With the module area $A_{\text {module, }}$ it is possible to adjust the equivalent circuit efficiency $\eta_{\text {circuit }}$ to the module efficiency $\eta_{\text {module }}$ :

$$
\eta_{\text {module }}=\eta_{\text {circuit }} \cdot \frac{A}{A_{\text {module }}} .
$$




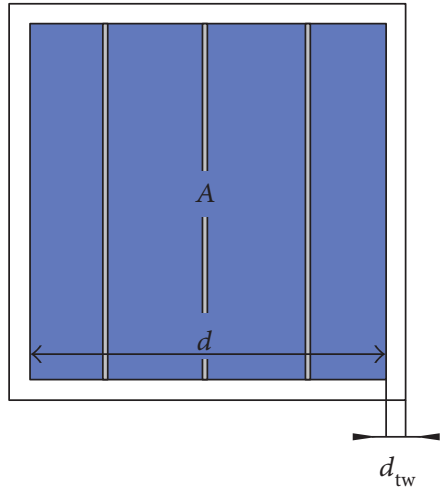

(a)

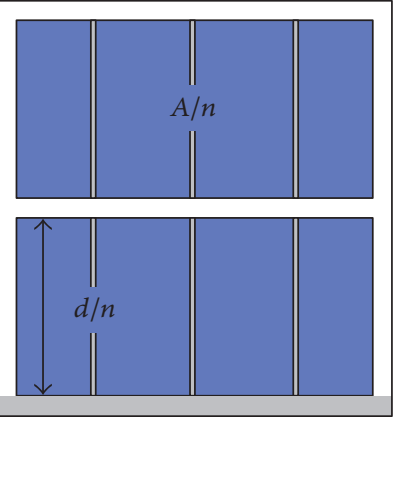

(b)

Figure 3: Increasing module area due to cell separation (grey stripe on (b)). The blue area represents the cell area, the space around the cell represents the tab width $d_{\mathrm{tw}}$, and the sum of both areas represents the module area. (a) Whole cell; (b) two half cells (i.e., $n=2$ ).

This adjusted module efficiencies are comparable with each other. However, it must be taken into account that the surface of the tabs between the partial cells is not a dead surface and the light reflected from the backsheet results in an increased $I_{\mathrm{sc}}$. The simulation relative to the backsheet reflectance is presented in the following section.

2.4. Backsheet Reflection. In order to estimate the backsheet reflection, a simplified model was developed (see Figure 4). The diffuse reflection of the normal incident light on a backsheet is assumed. The reflection angle $\rho$ is in the range of $-90^{\circ}$ to $90^{\circ}$.

The presented model uses the Lambertian cosine law for the backsheet reflection $I_{\mathrm{LB}}$ and the Fresnel equations for the reflection $I_{\mathrm{FR}}$ on the top of the front glass. A backsheet reflectance of 0.8 was obtained [7]. Since the difference between the refractive index of EVA and glass (1.497 versus 1.528 at $500 \mathrm{~nm}$ blackbody peak for $5780 \mathrm{~K}$ ) is very low, the interface EVA/glass is neglected $[8,9]$. For the whole thickness $\left(d_{\mathrm{tot}}=4 \mathrm{~mm}\right)$, a refractive index of 1.51 was chosen. A further simplification was made: since the backsheet of a real module lies under the cells and another layer of EVA, in this model, a backsheet at the same level of the cell surface was assumed.

Figure 5 displays the relation of the Lambertian radiation and the Fresnel reflection depending on the reflection angle $\rho$. One can notice that the intensity peaks are opposite from each other. The Lambertian reflection has its peak perpendicular to the surface at $\rho=0^{\circ}$. However, the Fresnel back reflection is increasing with the angle $\rho$ and achieves total reflection at about $42^{\circ}$. The following equations were used to calculate the intensity of the reflected light depending on its incident angle $\rho$.

The backsheet reflection intensity with a reflectivity of 0.8 is given by

$$
I_{\mathrm{LB}}(\rho)=0.8 \frac{\pi}{360} \cos \rho \text {. }
$$

Before the Fresnel reflection intensity can be calculated, the refraction angle $\beta$ must be determined.

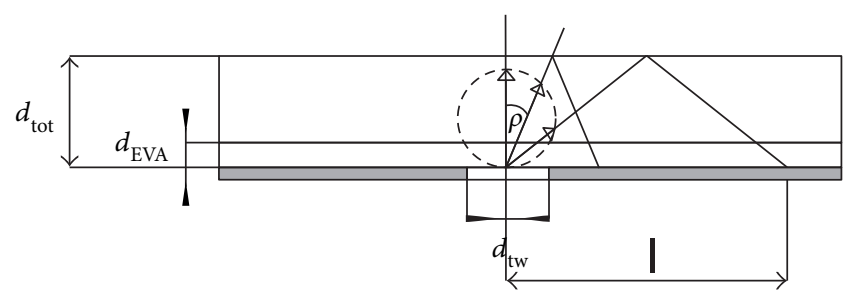

Figure 4: Model for the backsheet reflection. A normal incident beam of light is diffuse reflected from the backsheet with an angle $\rho$ between $-90^{\circ}$ and $90^{\circ}$. Fresnel back reflection on the top of the front glass finds place.

$$
\beta(\rho)=\sin ^{-1}\left(\frac{n_{1}}{n_{2}} \sin \rho\right) .
$$

The Fresnel equation is defined for the parallel and the normal polarized light. For the unpolarized sunlight, the mean of these two modes could be used to obtain the Fresnel reflection intensity:

$$
\begin{aligned}
I_{\mathrm{FR}}(\rho)=\frac{1}{2} \cdot & \left(\left(\frac{n_{1} \cdot \cos (\rho)-n_{2} \cdot \cos (\beta)}{n_{1} \cdot \cos (\rho)+n_{2} \cdot \cos (\beta)}\right)^{2}\right. \\
& \left.+\left(\frac{n_{2} \cdot \cos (\rho)-n_{1} \cdot \cos (\beta)}{n_{2} \cdot \cos (\rho)+n_{1} \cdot \cos (\beta)}\right)^{2}\right) .
\end{aligned}
$$

The distance $l$ travelled by light after two reflections (see Figure 4) is given by

$$
l(\rho)=2 d_{\mathrm{tot}} \cdot \tan (\rho) .
$$

The illuminance caused by the backsheet reflection is the product between $I_{\mathrm{LB}}$ and $I_{\mathrm{FR}}$ and thus depends on the reflection angle $\rho$ :

$$
I(\rho)=I_{\mathrm{LB}} \cdot I_{\mathrm{FR}} .
$$

From (10) and (11), the illuminance distribution on the middle of the tab can be calculated as a function of the length: $I=f(\rho(l))$. The length-dependent reflection is in the range of 


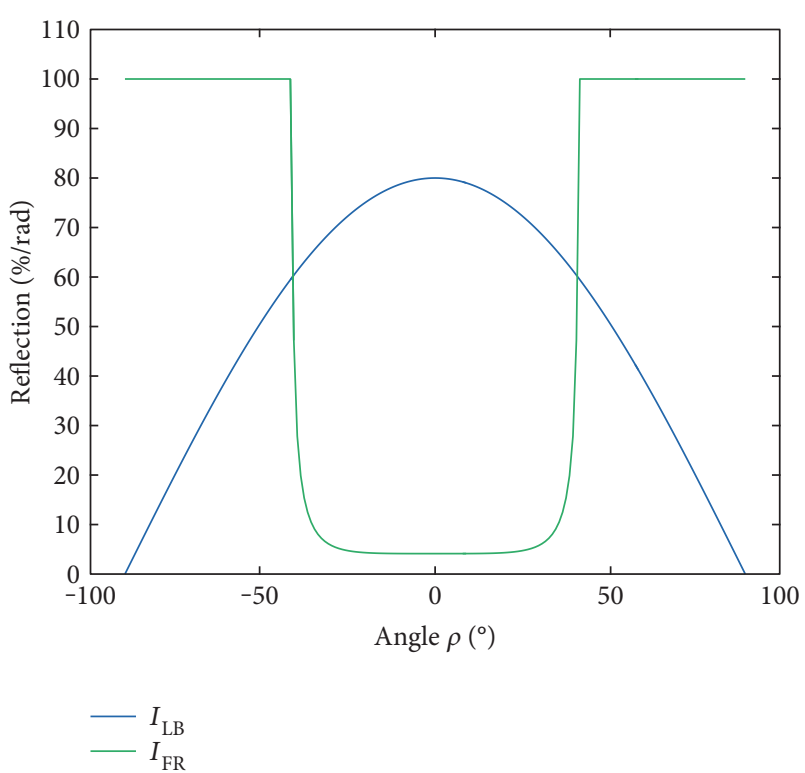

FIGURE 5: Reflection of the backsheet via Lambertian reflection $I_{\mathrm{LB}}$ (blue) and reflection on the glass $I_{\mathrm{FR}}$ via Fresnel equation (green).

$\mathrm{mm}\left(7.2 \mathrm{~mm}\right.$ corresponds to $\left.42^{\circ}\right)$, which is very short in comparison to the common module dimensions. That is why the reflection is integrated to infinity. This approach causes an overestimation next to the edges of the solar module. Nevertheless, the majority of tabs are in the middle of the module whereby the whole reflection intensity will hit the module again. Further, back reflection especially on the solar cells or other tabs has not been carried out. The additional gain due to the back reflection $P_{\mathrm{BS}}$ is calculated via the following equation:

$$
P_{\mathrm{BS}}=\eta_{\text {circuit }} \cdot \frac{A_{\text {module }}-A}{A_{\text {module }}} \cdot \int_{-\infty}^{+\infty} I(l) d l .
$$

This extra gain $P_{\mathrm{BS}}$ results in back reflection adjusted module efficiency by using (4) and (6):

$$
\eta_{\text {module }, \mathrm{BS}}=\frac{P_{\mathrm{BS}}+P_{\mathrm{mpp}}}{\left(1000\left(\mathrm{~W} / \mathrm{m}^{2}\right)\right) \cdot A_{\text {module }}} .
$$

\section{Results}

3.1. Circuit Simulation. 16 different circuits with $n$-times $1 / n$ partial solar cells for two different cell qualities at a given irradiance (i.e., two different photocurrents) were simulated as described in Section 2.2. Figure 6 shows the module efficiency, while increasing the amount of cell partitions. The underlying behavior is described in (1). The series connection increases the resistivity of the whole string (resistivity sum of $n$-times $1 / n$-sized cells), while the current decreases. Due to the squared influence of the current, a power improvement while using smaller cells is observable. Both cell qualities (i.e., higher and lower photocurrent) present the same trend. After a significant efficiency gain

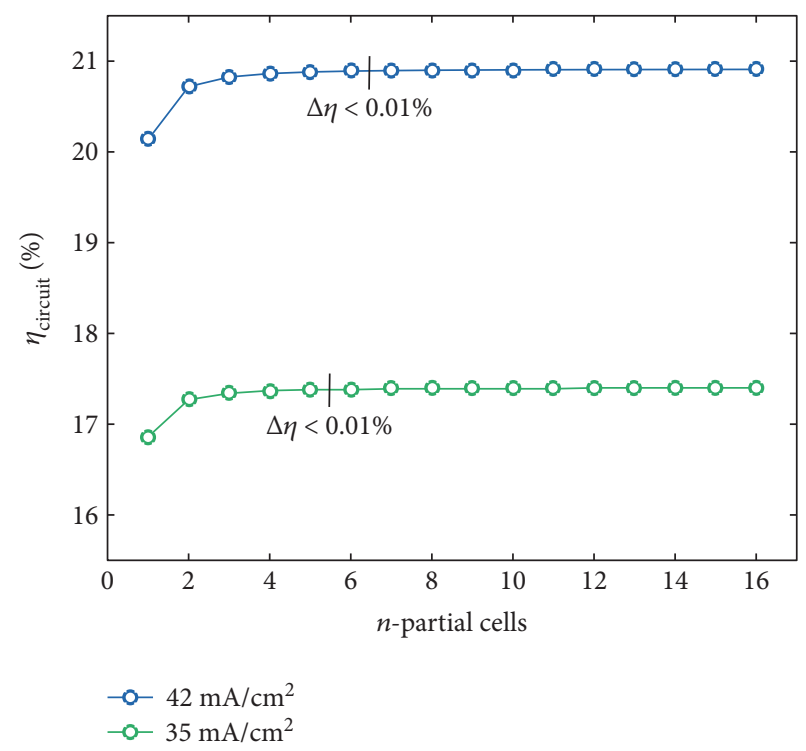

FIgURE 6: Module efficiencies for different cell partitions ( $n$-times $1 / n$ partial solar cells) and two different cell qualities.

(about $0.5 \%$ absolute value) from $n=1$ to $n=2$ (cell halving), a further gain is barely achievable.

The efficiency gain between $1 / 6$ and $1 / 7$ cells is below $0.01 \%$ absolute for a photocurrent of $42 \mathrm{~mA} / \mathrm{cm}^{2}$. For less efficient cells $\left(35 \mathrm{~mA} / \mathrm{cm}^{2}\right)$, this small increase is already achieved by $1 / 6$ cells. However, this quantity is not the optimum by far. While increasing the amount of partial solar cells, the area of the tabs between each cell increases too and the module area with it. That is why the module area must be normalized via (5) and (6). Such normalizations are only necessary for the conventional module applications. The so-called "shingle-like modules" use no tabs between the cells (only between the strings) [5]. The series connection is realized by stacking one edge over another like a roof shingle. With the help of this module design, the efficiencies shown in Figure 6 are nearly possible because of a neglectable area adjustment (only interstring spacing). Considering the previous-mentioned losses due to the cell separation of around $1 \%$ rel. and comparing them with the achievable gains, the optimum is in the range of $1 / 5$ to $1 / 6$ cells for shingled module applications.

3.2. Tab Width Normalization. The normalization of the tab width refers to the entire module surface of the simulated one-cell module. Figures 7 and 8 show the module efficiencies after the tab width compensation, for the two cell qualities.

The model uses the same width between strings, frame, and partial cells (tab). Three different tab widths, 1, 1.5, and $2 \mathrm{~mm}$ were simulated. This procedure ensures the tab width optimization [6]. It is clear that the tab width strongly influences the area-adjusted efficiency $\eta_{\text {module }}$. Since the module area steadily increases (see (5)) and the additional efficiency gain strongly decreases, the best efficiency is already achieved in the range of the half cells, while observing conventional 


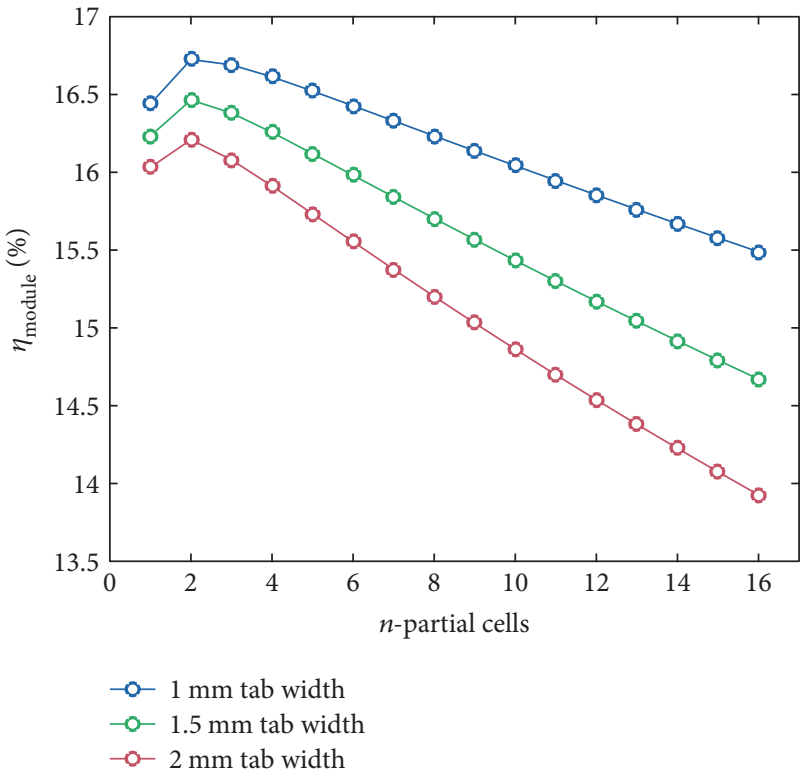

Figure 7: Area-adjusted module efficiency $\left(35 \mathrm{~mA} / \mathrm{cm}^{2}\right)$.

modules. Not even a heavily reduced tab width of $1 \mathrm{~mm}$ is able to compensate this effect.

3.3. Backsheet Reflection. The backsheet reflection can be calculated with the (7), (8), (9), and (11). This approach allows the calculation of the usable reflection depending on the distance $l$ from the middle of the tab width. In Figure 9, this dependence is illustrated. The very low reflectance from the area between -7.2 and $+7.2 \mathrm{~mm}$ (i.e., $\rho(l)$ between $-42^{\circ}$ and $+42^{\circ}$ ) allows neglecting the tab width in the calculation of the illuminance distribution $I(l)$. In total, $38.26 \%$ of the reflected light from the backsheet area can be used on the active solar cell. In order to achieve an estimation for large-size modules, the border of the module is neglected (integration over an infinite interval in (12)). For every tab, the full reflection on both sides was considered. As a reason of the low reflection intensity on the neighbored tabs and the high cell-to-tab-surface ratio, the second back reflection on the next tab was not considered. An efficiency gain of around $1.5 \%$ rel. is achieved due to the backsheet reflection on a $2 \mathrm{~mm}$ tab width. This value fits to other publications on backsheet reflections [7].

The additional gain $P_{\mathrm{BS}}$ (12) was added to the previous calculated efficiencies (see (13)). The resulting efficiencies for both cell types are represented in Figures 10 and 11. It is remarkable that optimal cell size is still the half cell. Only by the highest cell quality $\left(42 \mathrm{~mA} / \mathrm{cm}^{2}\right.$ photocurrent) and the narrowest tab width $(1 \mathrm{~mm})$, a very little benefit in the case of the one-third cells is observable (see Figure 11). For the less-efficient cells $\left(35 \mathrm{~mA} / \mathrm{cm}^{2}\right.$ photocurrent) and a tab width of $1 \mathrm{~mm}$, the efficiency is the same for half and one-third cells (see Figure 10). For bigger tab width, the use of half cells remains the best option. Even without taking the manufacturing process into account, this analysis leads to the conclusion that the use of half cells is the

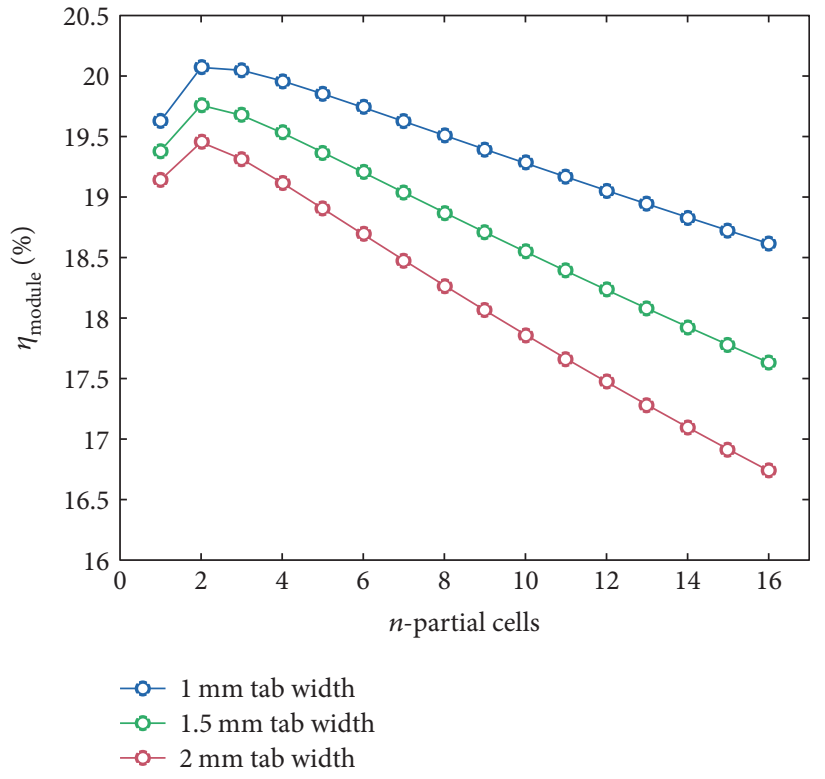

Figure 8: Area-adjusted module efficiency $\left(42 \mathrm{~mA} / \mathrm{cm}^{2}\right)$.

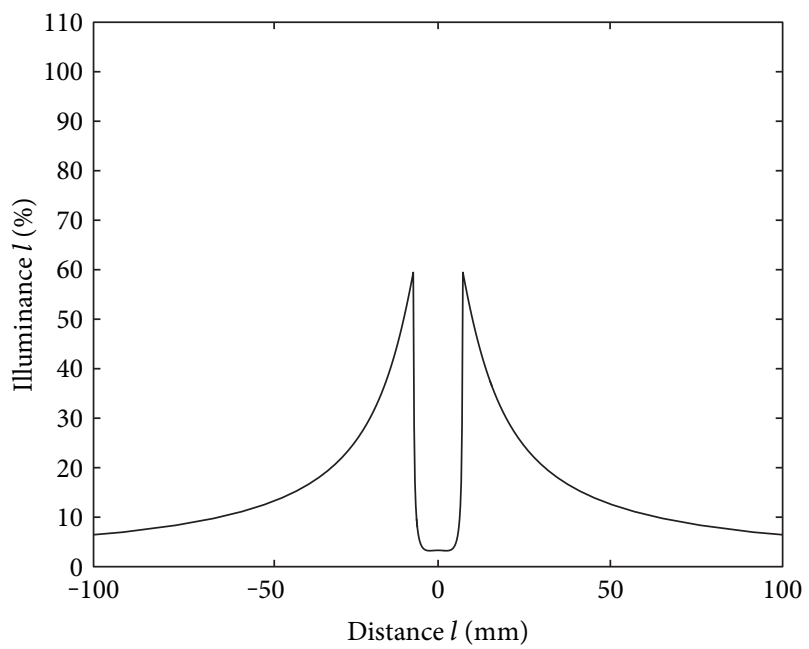

Figure 9: Distance-dependent backsheet reflection intensity. $l=0$ corresponds to the middle of the tab.

optimal approach for efficiency optimization, while not using shingled modules.

\section{Discussion}

The use of partial solar cells causes an ohmic loss reduction. The smaller the cells, the smaller the loss of the cell string there is. However, the consumption of module space increases drastically by increasing the number of cell partitions. On a technical basis, the use of half cells is the best option. A comparison between the half and the one-third cells shows that the loss due to an enlarged module area is already above the additional power gain due to the reduced ohmic loss. Even by employing very efficient cells and a 


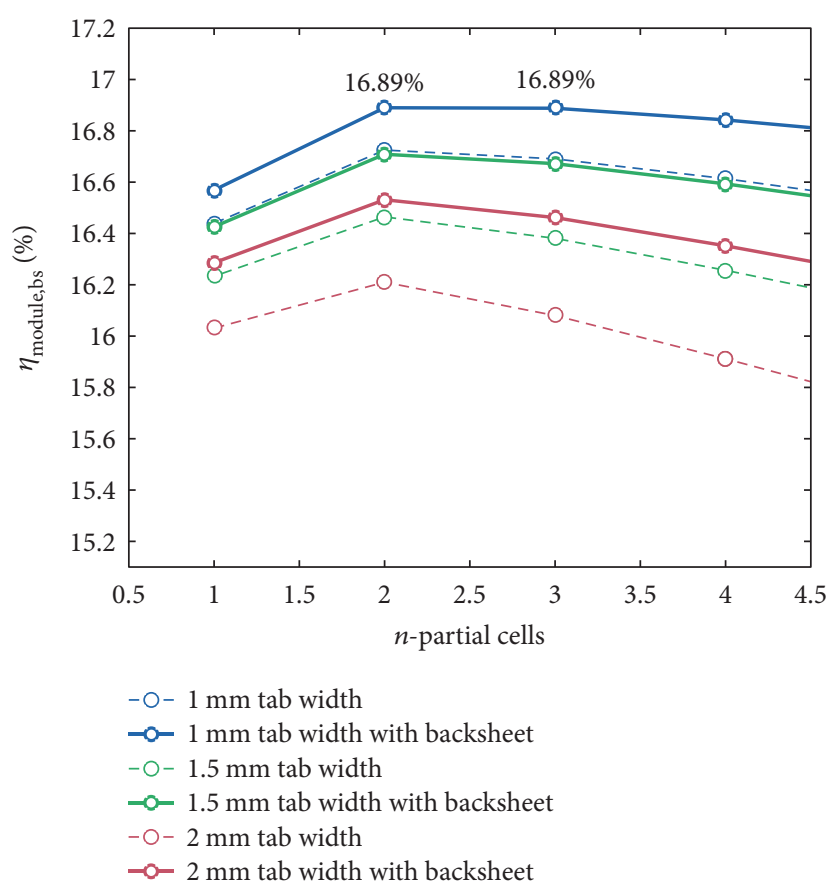

FIGURE 10: Backsheet and tab width-adjusted efficiency $\left(35 \mathrm{~mA} / \mathrm{cm}^{2}\right)$.

narrow tab width, only a very little gain in module efficiency can be achieved while observing one-third and half cells. This is especially true since in this study, a perfect separation of the solar cell without additional electrical losses is presupposed. Such high-quality electrical properties cannot be achieved, not even with new laser technologies, for example the thermal laser separation (TLS) [4]. But the use of partial solar cells has further disadvantages. While using partial solar cells, the effort in module fabrication increases. An additional cell cutting step must be inserted in the production chain. The effort in sorting, placing, and soldering increases too. It has to be taken into account that some of these steps are already doubled by the use of half cells. This statement points out that the use of partial solar cells will not be useful, if there is not a huge improvement in solar cell efficiency which leads to a higher photocurrent and due to this to an increased ohmic loss. But there is an exception. The so-called "shingle-like modules" use no tabs between the cells (only between the strings) [5]. With the help of this module design, the efficiencies shown in Figure 6 are nearly possible because of an almost neglectable area adjustment. In this case, a partial solar cell application at the range of 1/5-1/6 can be useful.

\section{Conclusion}

In this work, a simulation model for the determination of the efficiency by using partial solar cells was created. By diminishing the size of the cell partition, the additional efficiency gain steadily decreases, while the area consumption of the whole module increases. These two opposing effects have their optimum in the region of half cells. In this work, two cell qualities and three tab widths were simulated and all of them have their optimum at the half-cell setup. The effect of the backsheet reflection has been added afterwards, and

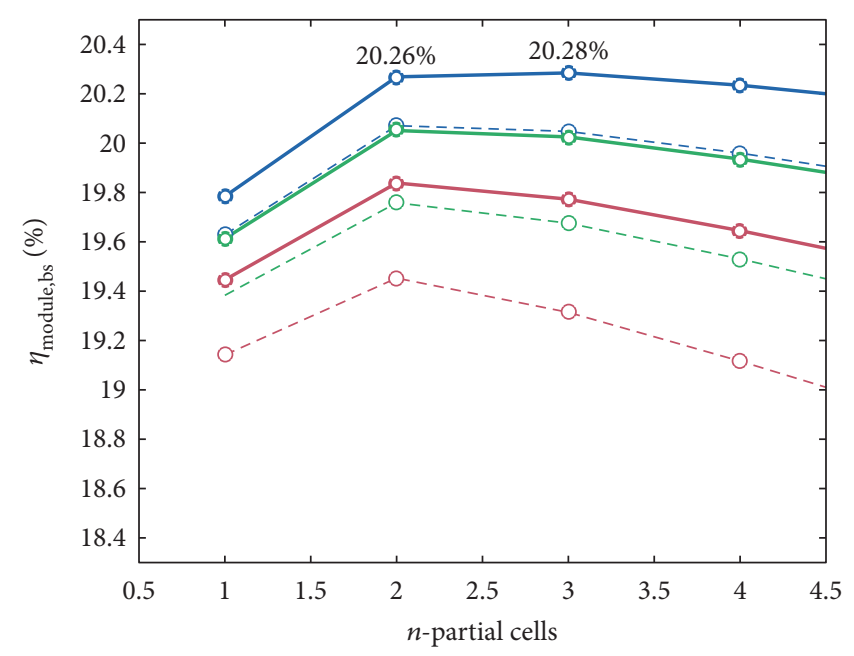

$$
\begin{aligned}
& -0-1 \mathrm{~mm} \text { tab width } \\
& -0-1 \mathrm{~mm} \text { tab width with backsheet } \\
& -\bigcirc-1.5 \mathrm{~mm} \text { tab width } \\
& -\circ-1.5 \mathrm{~mm} \text { tab width with backsheet } \\
& -\bigcirc-2 \mathrm{~mm} \text { tab width } \\
& -\circ-2 \mathrm{~mm} \text { tab width with backsheet }
\end{aligned}
$$

FIgURE 11: Backsheet and tab width-adjusted efficiency $\left(42 \mathrm{~mA} / \mathrm{cm}^{2}\right)$.

even with this additional gain, the partial solar cells with dimensions smaller than a half cell are not advantageous. Only the use of a high-efficiency solar cell in combination with a very narrow tab width $(1 \mathrm{~mm})$ reaches break-even for the one-third cell, in comparison to the half cell. However, this very small additional gain of $0.02 \%$ cannot compensate the additional manufacturing effort. For this reason, without a huge improvement in the cell efficiencies, the use of partial solar cells with dimensions below $1 / 2$ is not profitable. For shingled modules, the situation is more different. In such case, the use of partial solar cells up to $1 / 6$ can be beneficial depending on the electrical losses due to the separation process.

\section{Conflicts of Interest}

The authors declare that there is no conflict of interest regarding the publication of this paper.

\section{Acknowledgments}

This work was funded by the German Ministry of Education and Research (BMBF) under Contract no. 03FH005IX4.

\section{References}

[1] S. Guo, J. P. Singh, I. M. Peters, A. G. Aberle, and T. M. Walsh, "A quantitative analysis of photovoltaic modules using halved cells," International Journal of Photoenergy, vol. 2013, Article ID 739374, 8 pages, 2013.

[2] J. Mueller, D. Hinken, S. Blankemeyer et al., "Resistive power loss analysis of PV modules made from halved $15.6 \times 15.6 \mathrm{~cm}^{2}$ silicon PERC solar cells with efficiencies up to $20.0 \%$," IEEE Journal of Photovoltaics, vol. 5, no. 1, 2015. 
[3] R. J. Handy, "Theoretical analysis of the series resistance of a solar cell," Solid-State Electronics, vol. 10, no. 8, 1967.

[4] S. Eiternick, F. Kaule, H.-U. Zühlke et al., "High quality half-cell processing using thermal laser separation," Energy Procedia, vol. 77, 2015.

[5] D. Pearce, D. Hollars, and R. Cleereman, "Shingle-like photovoltaic modules," US Patent 20140150843, 2012.

[6] H. Hanifi, D. Dassler, J. Schneider, M. Turek, S. Schindler, and J. Bagdahn, "Optimized tab width in half-cell modules," Energy Procedia, vol. 92, 2016.

[7] S. Ponce-Alcántara, A. Vivas, and G. Sánchez, "Optical characterization of backsheets to improve the power of photovoltaic modules," in International Photovoltaic Power Generation Conference (SNEC), pp. 20-22, Shanghai, China, 2014.

[8] K. R. McIntosh, J. Cotsell, J. Cumpston, A. Norris, N. Powell, and B. Ketola, "An optical comparison of silicone and EVA encapsulants for conventional silicon PV modules: a raytracing study," in 2009 34th IEEE Photovoltaic Specialists Conference (PVSC), pp. 000544-000549, Philadelphia, PA, USA, 2009.

[9] M. Rubin, "Optical properties of soda lime silica glasses," Solar Energy Materials, vol. 12, 1985. 

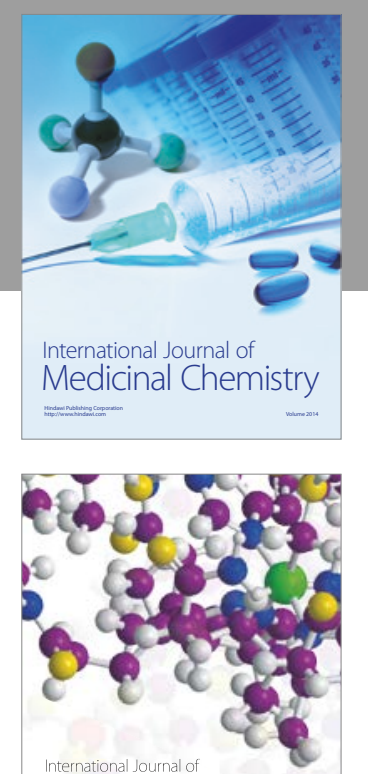

Carbohydrate Chemistry

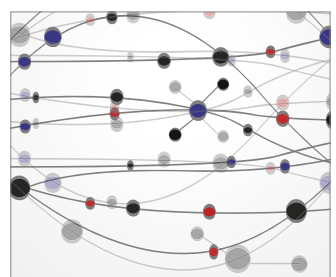

The Scientific World Journal
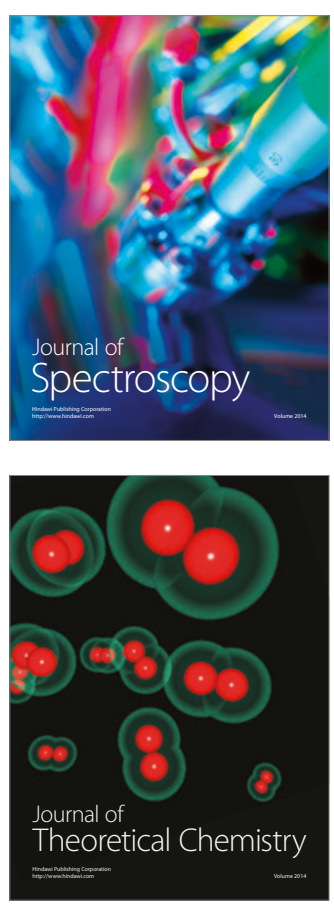
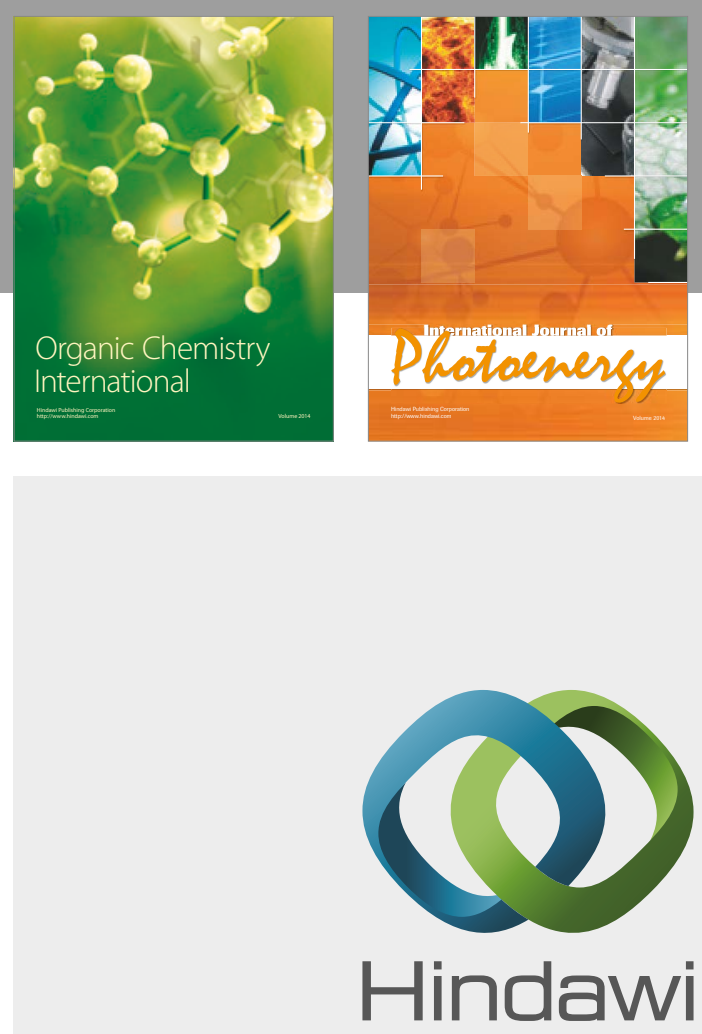

Submit your manuscripts at

https://www.hindawi.com

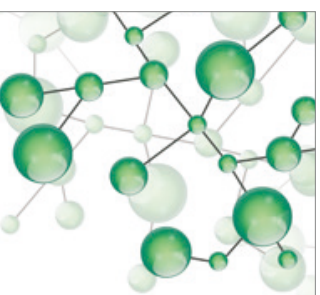

International Journal of

Inorganic Chemistry

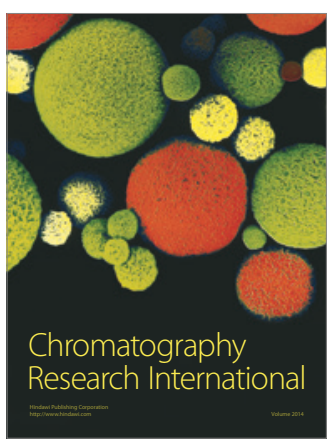

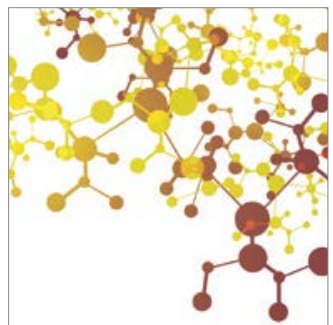

Applied Chemistry
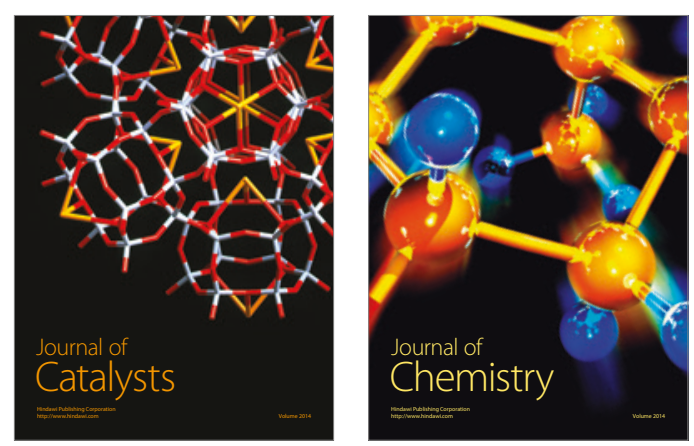
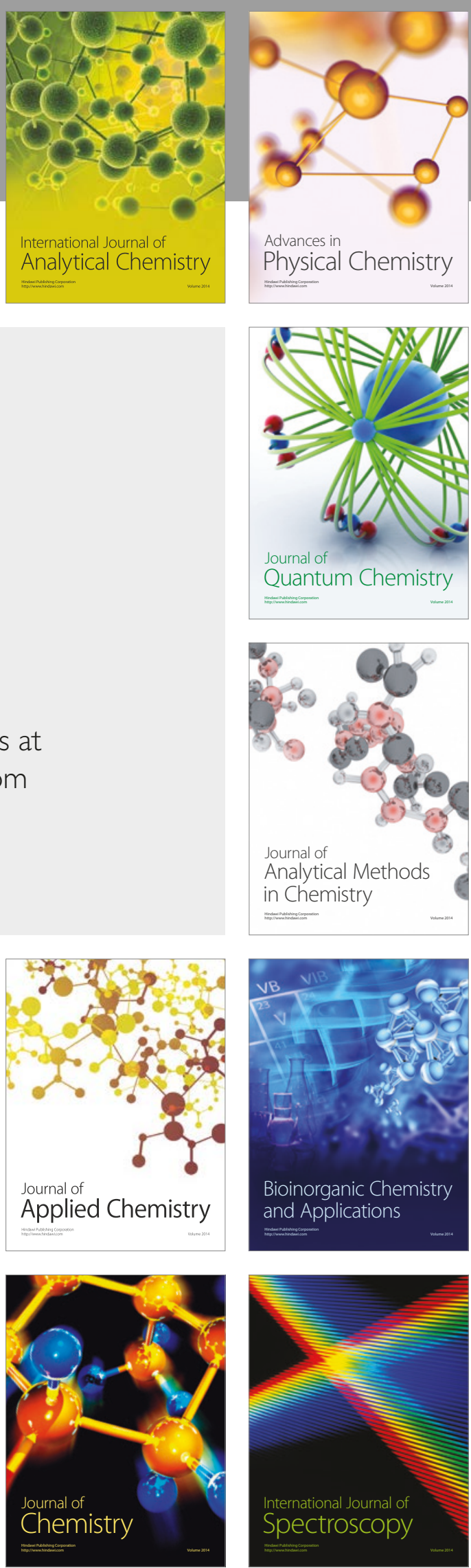